\title{
Comparison of the Effect of Major- Versus Minor-Keyed Music on Long-Term Declarative Memory in High School Students
}

\author{
Anita Sayar
}

Faculty Mentor: Dr. Hamid Sayar, Department of Medicine, Indiana University School of Medicine

\begin{abstract}
This pilot study compared the effect of music played in major and minor keys on long-term declarative memory (LT-DM), which stores facts or concepts, in high school students. Major and minor keys are pivotal theoretical distinctions in music known to trigger different emotional responses. While the influence of specific genres of music on memory have been studied, possible effects of the tonality of music have not been explored. It was hypothesized that music would improve LT-DM, and music played in the minor key would elicit a greater improvement than the major. A total of 21 volunteer high school students were equally randomized between two groups. Each group completed a control and an experimental LT-DM test. Tests comprised of a reading phase, where students studied a standardized passage, and a multiple-choice question phase seven days later, where their LT-DM of the studied text was examined. The reading phase of the control test was conducted in a quiet environment. During the reading phase of the experimental test, a piece of piano music was played. The same music was played in the major key for one group and in the minor key for the other. A trend towards better memory retention with the minor-keyed music was observed when compared to memory retention with the major-keyed music. The difference between the two groups of improvement with music, however, did not meet statistical significance $(\mathrm{p}=0.31)$. A larger complementary study may provide more definitive information regarding comparative effects of major and minor musical keys on LT-DM.
\end{abstract}

KEYWORDS: music, long-term declarative memory, major key, minor key, LT-DM

\section{INTRODUCTION}

$\mathrm{M}$ emory is an important capability of human cognition. Education and modern-day activities require its use. Music is also important in society, popularly integrating itself at the cultural level (Hall, 1998) and captivating emotions. The interpretation of music by individuals showcases the advanced dimensions of mental processing. Music and memory affect each other in various ways, with the relationships between the two phenomena just beginning to be discovered. These two aspects of human design, memory and music, are worth investigating and further understanding. There is a plethora of mysteries regarding how memory and music affect each other. The results of this research scientifically combine these two critical aspects to reach a further understanding of the relationship between music and memory.

\section{History and Definitions}

Human memory is classified into various types. The two main types are short-term memory (STM) and long-term memory (LTM). STM is stored for a few seconds and consists of the quick recognition and recall of information, such as memorizing words and numbers on a list or details in pictures. LTM is used to store information over a longer period of time, anywhere from a few hours to potentially forever (Mastin, 2010). This can include memories of childhood experiences, tasks such as practicing an instrument or a sport, and general storage of facts or concepts. Specifically, long-term declarative memory (LT-DM or DM) is the branch of memory that stores facts or concepts; it is declarative because the information can be consciously recalled (Eichenbaum, 1997).

The discovery of declarative memory as distinct from other forms of memory is a rather recent achievement. Understanding declarative memory from a neuropsychological perspective began with studies on the patient HM during the early- and mid-twentieth century. After removal of most of the hippocampal region of his brain and associated medial temporal-lobe structures, HM suffered a profound impairment in anterograde learning. His memory was severely hindered, regardless of efforts to regain it; however, he showed normal retention of memories acquired years before the surgery. Early observations of HM indicated that the hippocampal region was important to only some aspects of memory. In present day, it is known that declarative memory is controlled by a specific brain system, including areas of the cerebral cortex and hippocampal region, that make very distinct functional contributions to memory processing. These neuropsychological processing mechanisms mediate the organization of memories, which discriminate declarative memory from other memory types (Eichenbaum, 1997).

Western music is often organized into major and minor tonalities, or the incorporation of major and minor musical keys (MM). A key (written as a key signature) revolves around a scale, a sequence of ascending or descending notes or pitches. These scales can be major or minor in nature. A major scale exhibits a specific pattern in the intervals (physical and auditory spaces between notes) of the note sequence. A minor scale exhibits a different pattern from a major scale. Accordingly, major and minor scales compared side-by-side sound different to the ear.

Keys that are written in compositions indicate which scale (sequence of notes) should be played in the composition (Wharton \& Shaffer, 2014). Scales will always return to their original starting note when the goal is to perform an ascending and descending sequence. Moreover, both keys and scales are named for the first and last note of their sequence, which is always the same. For example, the key of $C$ major indicates that the notes to be played in the music are part of a scale beginning and ending with the note $\mathrm{C}$. It is important to remember that the scale determines the key (Figure 1).

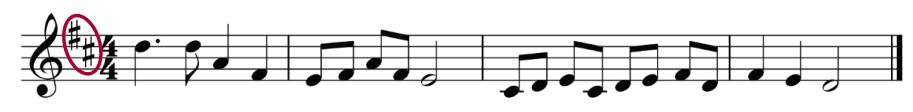

Figure 1.

Key signature (circled). Key signatures are expressed by sharps and/or flats (circled above), which dictate the scale of the piece. 
Another central element to Western music is transposition, the modulation of one key into another key. This is achieved by rearranging the notes in the composition to fit the pattern/sequence (scale) of the desired key. Transposing a composition preserves the intervallic arrangement (spaces between notes) so that the melody (main tune of the piece) will remain, yet the music will sound different due to a different base pitch (Wharton \& Shaffer, 2014). By transposing (modulating) the key, the scale has changed, and the music will start on a different note/pitch. While the notes have changed, the pattern (interval or spaces) has not. A key may be modulated into any other key, regardless of major or minor. For instance, a musical composition in the key of $C$ major may be transposed to $C$ minor or $D$ major or $F$ minor or $B$ major. The melody will remain the same, yet it will sound different to the ear.

Major and minor keys and chords have not always been essential components of Western music. Before the seventeenth century, most music was "modal" in nature; that is, it used scales that included but were not limited to major or minor. By the last third of the seventeenth century, Corelli, Lully, and other composers of the time were writing music that is called "tonal," or not existing within a fixed scale, but instead operating on geometrically related tones, each with a frequency of a fixed proportion familiar from music of the eighteenth and nineteenth centuries and onward. This "tonality" evolved gradually. The long-standing use of the "tonality" technique, stemming from Aeolian and Ionian modes, eventually bred a consistent set of routines in music composition that would be codified into a theory. In the early eighteenth century, JeanPhilippe Rameau was the first to describe these routines as "major" and "minor" keys. This was a revolutionary idea at the time, but is now considered the staple of modern music theory (Grout \& Burkholder, et. al, 2010).

In this study, an originally major-keyed song was modulated to a minor key, and both were used to compare the effect of MM on LT-DM.

\section{LITERATURE REVIEW}

\section{Music and Brain Engagement}

Music is known to influence the brain, and research continues to expand the scientific aspects of this notion. Sridharan and Levitin et. al, (2007) used functional Magnetic Resonance Imaging (fMRI) on subjects listening to short symphonies by an obscure 18th-century composer to explain how music can be involved with focusing attention, making predictions, and updating events in memory. The fMRI scans (Figure 2) show how music can continuously increase brain activity over time.

Researchers proposed that the process of listening to music could be a way the brain sharpens its ability to anticipate events and sustain attention (Sridharan \& Levitin, et. al, 2007). If music is thought to sustain attention and memory may be influenced by the sustainment of attention, then music may also play a role in retaining memory.

\section{MM and Emotions}

MM has a direct psychophysiological effect on human perception. An international workshop (Cook, 2006) published an experiment in which undergraduate students were presented major and minor chords and asked to evaluate their emotional feelings (a chord is a set of notes played together that may also be MM). Major chords were evaluated as "happy and bright," whereas minor chords were evaluated as "dark and sad." These results were consistent with all the participants, regardless of musicianship, and other previous

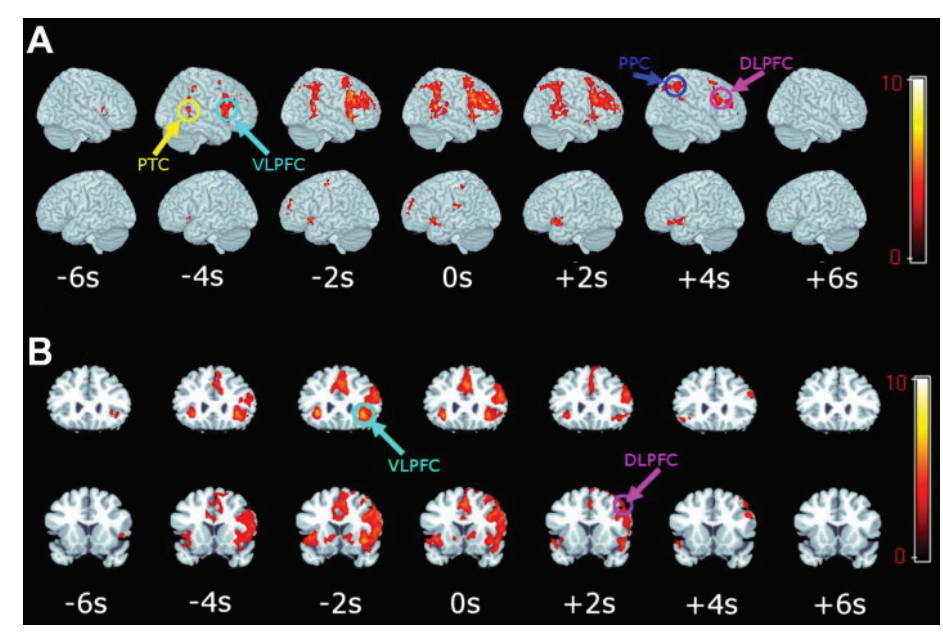

Figure 2.

fMRI scans. Brain activity in the ventral fronto-temporal and the dorsal fronto-parietal network (indicated in red and by arrows) increased to peak levels in between musical transitions; such activated areas are regions related to anticipation, prediction, and processing of memory.

Note: From Sridharan, et. al, 2007 in Neuron. Reprinted with permission.

research. Meyer's idea of harmonic "tension" was the first explanation for this perception. Harmonic tension occurs when a chord follows a certain pattern, signaling a type of "expectation" or "anticipation" in the music, as in a major chord. When this anticipation is "denied" or "delayed," like in a minor chord, it creates a sort of psychological "tension" (Meyer, 1956).

Yet, the question remains as to why "tension" would be perceived as emotions in the form of "happy" and "sad." Cook proposes Ohala's theory of "Sound Symbolism," the result of an ancient evolutionary connotation in the human brain. This "sound symbolism" exists in human languages and animal vocalizations. Decreasing vocal pitch indicates strength and social dominance (commands, assertions), whereas increasing pitch signals defeat and social weakness (questions, uncertainty). In turn, major and minor chords are inherently positive or negative because their tonal structures have ancient evolutionary implications of high or low social status (Cook, 2006).

Expanding upon Meyer's idea of "harmonic tension," Cook's experiment, and "Sound Symbolism," the Musical Equilibration Theory asserts that all emotions tied to music can be represented by empirical data, specifically, the emotions felt by the harmonies in music (Willimek, 2013). A large-scale multiphase research study conducted by Daniela and Bernd Willimek (2013) worked to support the Musical Equilibration Theory. Children of different ages were asked to report their spontaneous responses to major and minor chords. Children perceived the music containing major chords as courageous and comfortable, and the music containing minor chords as associated with loneliness and despair (Willimek, 2013). The way in which the children attributed a certain emotional character to musical harmonies was consistent with the results of Cook's experiment and Meyer's theory of "harmonic tension." This shows support for the notion that emotions felt by music are predictable and measurable among a human population.

\section{Emotions and Memory}

Experiments in modern psychology establish the basis that emotional events tend to be retained more strongly than other everyday occurrences. Rickard and Wong et al. (2012) demonstrated 
this influence, termed the "neuromodulatory effect," with the accompaniment of relaxing or arousing music to an emotional story heard by adult research participants who were then LTMtested. Relaxing music significantly reduced the retention of the emotional story in participants, whereas arousal music enhanced it. The results show the capacity of arousing music to enhance the strength of emotional memory. The measurement of LTM in this study is significant, as it is seldom researched in relation to memory and furthermore highlights the notion that effects may be long-term. It is reasonable to infer that arousal music (a way of brain engagement), which may be perceived in a psychological and emotional sense of "anticipation" or "tension" as mentioned in previous studies on MM and emotions (Meyer, 1956), may influence memory retention.

\section{Other Factors}

There are other factors that influence the effect of music on human memory, one being age, and another the overall distraction level of music. Reaves and Graham et al. (2014) conducted an experiment in which young (18-30 years) and older adults (60-75 years) listened to music as opposed to silence while simultaneously studying face-name pairs to test associative memory (a form of STM). All participants rated music as more distracting to their performance, but only older adults' associative memory performance was definitively impaired by the music. One assumption may be that younger populations are more likely to benefit from musical presence in regard to memory.

Another element to consider is the effect of personality traits on comparative music and memory experiments. Furnham and Trew et al. (1999) examined the effects of music on the performance of introverts and extroverts in cognitive tasks, determining that the performance of introverts was impaired by the introduction of music, whereas the performance of extroverts was enhanced. These results may act as limitations to future research, as personality may affect the outcome of memory if it affected cognitive tasks.

A third factor that influences music and cognitive/memory experiments is musical ability. Virtala et al. (2012) discovered that musical training facilitates neural discrimination of $\mathrm{MM}$ in 13-year-old children, indicating that there are cognitive (and possibly memory-related) differences in musically trained students as opposed to non-musically trained students. Comparatively, Ho and Cheung et al. (2003) found that children five and under, when musically trained, had improved verbal, but not visual, memory. When the children were followed a year later, those who had begun or continued music training demonstrated significant verbal memory improvement, and students who discontinued the training did not show any improvement. While the study confirms longterm retention of STM in musically trained individuals, only parts of STM were improved, raising questions about the consistency of musical ability in STM.

\section{Previously Studied Variables}

Several variables have been studied in music- and memory-related research. One such variable is general instrument and/or voice accompaniment. Silverman and Schwartzberg (2014) tested the recall of STM information paired with six different melodies on 60 university students. Melodies were composed and recorded using female and male voices with three types of accompaniment: guitar, piano, and no accompaniment. Researchers found that the participants had more accurate STM recall during male voice/ piano and no accompaniment conditions and least accurate recall during female voice/guitar accompaniment conditions. This suggests that piano and/or male voice accompaniment is a better tool for measurement regarding memory. A song played and recorded on the piano without voice accompaniment was used in this experiment to facilitate the fairest environment for recall.

Genre is another important variable that is often considered. While experiments studying how multiple genres affect STM have been proposed (Andrews \& Christerson, et. al, 2009), these results remain unclear and varied among studies; studying one genre is preferred (Hall, 1998). Often, this lone genre is mediated by cultural or ethnic ties; Hall (1998), after understanding from research that rap music is popular among African-American youth, found that African-American children of age groups ranging from 7-12 could recall a song's lyrics equally well by listening regardless of whether they understood the meaning of the lyrics. Consequently, music of a specific genre may be more inclined to one group than another, but memory is consistently enhanced with music.

Musical tempo yields contradictory findings. Jurkovic and Anderson et al. (2013) exposed adult participants to classical music at various tempos, measuring their heart and respiratory rates as they performed a STM test. The measurements of change in heart and respiratory rate showed no large variations, and there was no statistically supportive evidence that musical tempo affects memory retention or changes in heart and respiratory rate. However, Balch and Lewis (1996) tested STM and changing tempos as well, finding that STM was enhanced when music stayed at the same tempo, but not as a direct cause. Tempo was found to influence the arousal component of mood, and recall was higher in a mood context consistent with a given tempo. Despite contradictions, research overall supports the idea that a certain mood (linked to emotion) may evoke certain memories through specific brain engagement. Therefore, it is possible that certain moods may be associated with a stronger recall of information. The brain, when exposed to information in accompaniment of emotionally provoking music, may have a better recall of the information later.

Through previous studies (Cook, 2006; Reaves \& Graham, et. al 2014; Sridharan \& Levitin, et. al, 2007), it has been shown that the important variables of this experiment are the emotional engagement and brain activity from MM, and its measurability in high school students through standardized LTM testing methods.

\section{OBJECTIVE}

Most studies on music and memory are related to genre, tempo, and musicianship (Hall, 1998; Jurkovic \& Anderson, et. al, 2013; Silverman \& Schwartzberg, 2014), or they investigate some branches of STM, but hardly any are LTM-focused (Meyer, 1956). MM has only been investigated cognitively (Cook, 2006), but no formal connections to memory have been made. Moreover, the studies mentioned were all conducted with either young children or adults at least 18 years of age. No research has been specifically directed towards high school students in any of the topics of MM and its relationship with memory, neglecting an important part of the population. High school students are highly engaged in academic activities requiring memorization skills and retention. Moreover, such students typically represent various layers of the general population, while students in higher level academic settings are usually more sociodemographically similar. Analyzing a more general population allows researchers to understand the broader impact of music on memory. The primary objective of this study was to compare the effect of MM on LT-DM in high school students. The study aimed to initiate an effort towards examining the hypothesis that music played in the minor key would evoke a stronger improvement in LT-DM than music played in the major key. 


\section{METHODOLOGY Study Design}

The study was conducted in a highly-controlled setting: an empty classroom, with equal preset conditions for all participants to allow an accurate depiction of the results and to eliminate environmental confounding variables. All students, regardless of grouping, were given the same control and experimental passages/tests, the seating was random, and other factors, such as speaker's volume level, were the same. Memory tests were standardized for both control and experimental phases (Memory Puzzle, Reading Comprehension Worksheets) (Appendix A). The only changing factor was the independent variable, i.e., MM. The research was both analytical and comparative in nature. It was analytical in its attempt to make a critical evaluation of the test score results and provide questions for further research. The research was also comparative, as it compared the control (no music) test to the major/minor tests and assessed statistical significance of the differences. In the experiment, the researcher directly controlled interventions or factors under study: one central location for the experiment process, memory tests, timing, and dates of meetings were all determined by the researcher. The allocation of students into major or minor experimental groups was randomized.

\section{Ethical Considerations}

This research was approved by the Carmel High School Institutional Review Board (IRB) through an extensive and thorough form outlining all research-related details. The study was anonymous and voluntary, eliminating personal bias. The anonymity and all other factors in the research were disclosed to all participants before they agreed to participate and were repeated during the experiment; participants knew they could refuse to participate or leave at any time. A thorough attempt was made to get the most representative sample, including recruiting as many students from each grade and gender as possible. To inform students of experiment meetings, they were required to sign up for a texting service. The students were informed that all personal account information would be deleted at the end of the experiment. To make sure the memory tests were sorted correctly with the participant, the students were assigned a number as identification. Additionally, students partook in a demographic questionnaire regarding grade, gender, and musical knowledge, but no personal information was revealed to outside parties. The students were not deceived in any part of the experiment, although MM was never revealed as to omit any student bias.

\section{Selection of Participants}

The target population was high school students, grades 9-12 at Carmel High School in Carmel, Indiana. Volunteer participants were selected by random recruitment during a school-wide study hall, Student Resource Time (SRT). A list of all the classrooms in the school with an SRT were obtained, numbered, and separated by grade level. A random number generator (True Random Number Service) was used to select numbers and thus corresponding classrooms for each grade from which volunteers were recruited. Any high school student was permitted to join, regardless of academic strength, musical knowledge, athletic abilities, or other factors. A stratified random sample of participants was obtained, since a limited number of students in each randomly-selected SRT volunteered to participate in the experiment. Some students refused to participate due to timing issues or other personal reasons. A food party incentive for all those who completed the experiment was planned to encourage participation. Students were told during the recruitment about the overall nature of the study, described as testing long-term memory in high school students with the involvement of music (although MM was not dictated). They were told about the timing of the experiment as a 10- to 15-minute session once a week during SRT for three consecutive weeks. Any subject who failed to attend all three of the sessions was disqualified.

\section{Procedure}

The recruited students were numbered consecutively and divided into two groups by the random number generator (True Random Number Service). One group was assigned the major key (known to students as "Group A"), and one group assigned the minor key (known as "Group B"). Groups A and B met at separate times and were from different SRT classes to minimize contact as much as possible. In the experiment, major/minor music was the independent variable (IV), and the scores from the memory tests were the dependent variable (DV). All sessions of the study were conducted in the same quiet room in Carmel High School with accessible speakers. Students were given proctored instructions by the researcher throughout all sessions of the experiment. Each group was assigned to have 3 sessions over three consecutive weeks ( $7+/-2$ days apart from each other). In the first session, each group was given the control passage, where no music was played (See Appendix A). The students were allotted 5 minutes to read and study the passage (Appendix A). The students were told to study it as if they were studying a text for school and to take the experiment seriously. During the second session, 7 +/2 days later, a 10-question multiple-choice test was given to the students assessing what they remembered from the control text. Multiple choice was chosen for its effective, non-biased method of measurement, and the 7+/-2-day period was chosen based on similar LTM-testing experiments' time periods (Rickard \& Wong et al., 2012). Additionally, during the second session and after the control test, the experimental text passage was provided to the subjects, again with five minutes to read and study. Both experimental and control passages were standardized memory assessment texts of similar difficulty levels (Memory Puzzle). This time, a piece of piano music was played while the students were studying the text. The same music was played in the major key for Group A and in the minor key for Group B (Figure 3). The musical file was an actual piano recording of the piece played by a pianist in the researcher's presence to ensure consistency (Appendix B). This piece was recorded in both its original major key, D major, used for Group A, and a minor, transposed version (D minor), used for Group B (Appendix B). The music used for the experiment was selected for its obscurity so that there would be no pre-familiarity bias in listening, and for its piano instrumentation, as previous studies indicated the piano's superiority to other instruments in effective memory retention improvement (Silverman \& Schwartzberg, 2014). On the third session of the experiment, after $7+/-2$ days, the last multiple-choice memory test over the experimental passage was administered without the presence of music (See Appendix C for scores). The study's purpose was to assess retention of material memorized under the influence of music, not to evaluate test performance while music played, therefore the test was rendered in a quiet environment. At the end, students were given a brief questionnaire to collect demographics data, such as gender, grade level, and musical knowledge (Appendix D).

\section{RESULTS}

A total of 21 students were tested, with 11 in Group A (major) and 10 in Group B (minor). Group A consisted of 9 females and 2 males, and Group B 6 females and 4 males (tables D1 and D2). The data were entered into the Victor Bissonnette software for statistical 


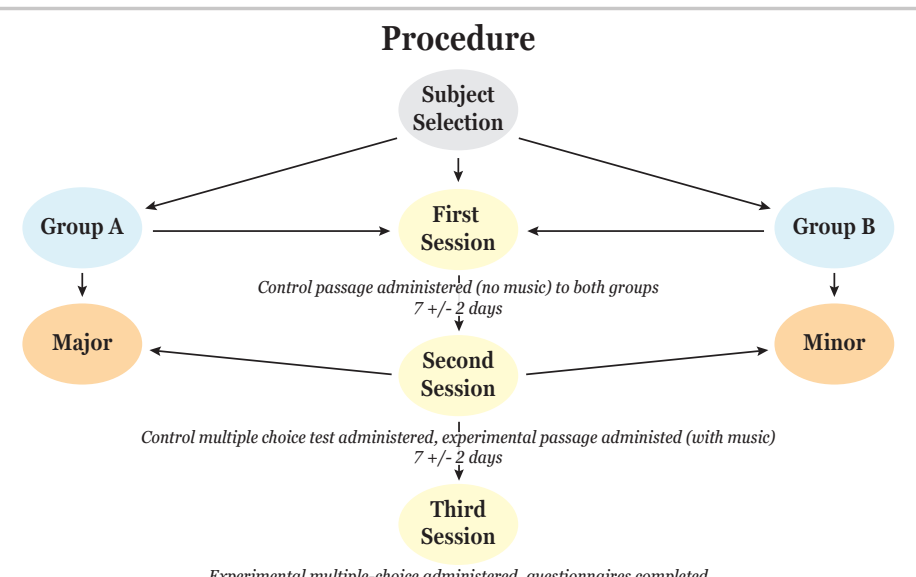

Figure 3.

Flow chart of procedure. After recruitment, subjects were randomly divided into Groups $A$ and $B$. All subjects completed the demographics questionnaire (Appendix D).

analysis (Bissonnette, 2017). First, a paired t-test was conducted for each individual group to evaluate the effect of major or minor music on memory. Both groups demonstrated a statistically significant improvement in the experimental test score compared with control ( $p=0.0078$ and $p=0.0107$, for groups A and $\mathrm{B}$, respectively). The means of the score differences between the control and experimental tests were calculated for each group, which were 1.0 point for Group A and 1.6 points for Group B. Then, an unpaired t-test was performed to analyze the difference between the means. There was no statistically significant difference between the means of the two groups ( $p=0.31$, confidence interval 95\%). However, considering the higher mean score difference in Group B (1.6) compared to Group A (1.0), it is possible that a larger sample size may have demonstrated a trend towards a better memory retention with minor-keyed music (Figure 4).

\section{STUDY LIMITATIONS}

A limitation of this study was the sample size. A trend toward greater improvement in LTM was observed in Group B compared with Group A. The difference could have possibly been statistically significant with a larger sample size. Thirty-five students originally agreed to participate, yet only 21 came to all meetings. There was an uneven distribution of students per grade, with upperclassmen females being overrepresented in both groups (see Appendix D). Possible environmental distractions during the exam, such as outside noises or even the MM music itself, could limit the results; out of the 21 total, eight students indicated on the questionnaire that the music played during the exam was distracting to some degree (Appendix D). It is important to note that the tests were performed in an experimental setting and can only be used as a model for an outcome in the real world. Finally, although effort was spent to choose standardized tests with the same level of difficulty, it cannot be ruled out that such improvement could have been as a result of a more difficult control test compared to the experimental test for both groups. However, both groups demonstrated a significant improvement with music; thus, it less likely for the same bias to have occurred twice in favor of the experiment.

\section{DISCUSSION}

Existing data support the notion that listening to music may affect DM (Rickard \& Wong, et. al 2012, Sridharan \& Levitin et. al 2007). LTM in particular is essential to learning and plays a substantial role

\section{Test Scores for Groups A and B}

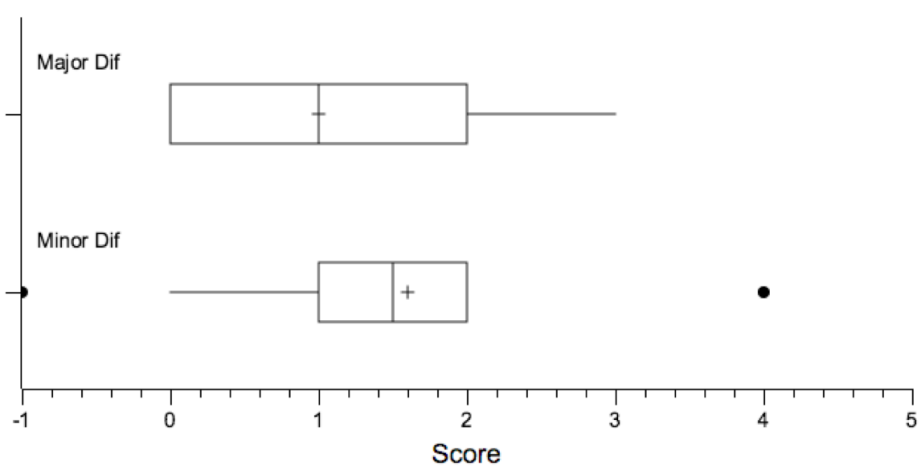

Figure 4.

Boxplot of the difference in test scores for groups A and B. The difference in scores across both groups are shown above, with the extremes at 0 and 3 points for the major group, and -1 and 4 points for the minor group.

in academic performance; therefore, methods to enhance it would be of high interest to many. Sporadic studies have examined the effect of factors, such as voice and piano accompaniment, music genre, and tempo, on STM (Silverman \& Schwartzberg 2014, Andrews \& Christerson et. al 2009, Hall 1998, Jurkovic and Anderson, et. al 2013); however, no previous studies have addressed the effect of music on LTM and, in particular, the potential advantage of a specific musical tone, scale, or key in improving this form of memory. This pilot study attempted to investigate this matter in high school students. High school students were chosen for their deep involvement in academic activities requiring strong memory retention and for their representation of a largely neglected population among whom no previous studies had addressed. Although a few subjects reported the played music to be distracting, this pilot study observed an average improvement in LT-DM when piano music was played during the study time compared to a quiet environment. The possibility that musically-trained individuals have more pronounced memory recall (Ho \& Cheung, et. al 2005) than those with little musical knowledge was not observed in this experiment, as all students improved rather equally point-wise despite various levels of musical knowledge. Since minor-keyed music typically evokes a darker mood and sadness, which may trigger a stronger emotional response than happiness and consequently a possible heightened memory recall, the presumption was that the music played in the minor key would improve LTM. This pilot study suggested a slight improvement in LT-DM with minor-key music when compared to major-keyed music; however, the difference did not satisfy statistical significance $(p=0.31)$. This could have been due to the limited sample size; therefore, larger-scale studies are required to further investigate the potential difference.

Based on the evidence presented, music may be considered an influential player in DM retention, and it is possible that minorkeyed music offers a slight advantage. Findings of this pilot study warrant a larger study to further investigate this matter. This pilot study warrants a next step, larger investigation to more definitively examine the hypothesis of improvement in LT-DM with music, and further with minor-keyed music. A next study may consider a greater generalized representation of high school students and counterbalancing tests to avoid potential bias. Such research will offer further insight into existing musical education procedures and practices involving memory improvement. The findings will be valuable to students, educators, and those interested in the field of memory improvement for pedagogical and academic purposes. 
Importantly, every individual, including those involved in academia and others in society, may be interested in improving memory retention via non-medicinal techniques. Furthermore, extensions of such experiments to the field of medicine may have implications in memory retention for cases of Alzheimer's disease or Attention Deficit Disorder as possible resources for improvement of LT-DM recall in patients.

\section{AUTHOR INFORMATION}

All correspondence should be sent to the first author: anitasayar@yahoo.com

\section{REFERENCES}

Andrews, H., Christerson, K., Crowe, M., \& Sparks, R. (2009, November 11). Draft 3: How Do Different Types of Music Affect Memory Recall? Retrieved November 23, 2016, from http://jrscience.wcp.muohio.edu/inquiry09/ProposalArticles/ Draft3.HowDoDifferentType.html

Balch, W. R., \& Lewis, B. S. (1996). Music-Dependent Memory: The Roles of Tempo Change and Mood Mediation. Journal of Experimental Psychology: Learning, Memory, and Cognition, 22(6), 1354.

Bissonnette, V. L. (2017, January). Stats Homework: A Statistical Package for Students (Version January 21, 2017) [Computer software]. Retrieved February 21, 2017.

Caldwell, G. N., \& Riby, L. M. (2007). The Effects of Music Exposure and Own Genre Preference on Conscious and Unconscious Cognitive Processes: A Pilot ERP Study. Consciousness and Cognition, 16(4), 992-996.

Cook, N. D. (2006). A Psychophysical Explanation for Why Major Chords are "Bright" and Minor Chords are "Dark.". In Proceedings of the First International Conference on Kansei (pp. 45-48).

Eichenbaum, H. (1997). DECLARATIVE MEMORY: Insights from Cognitive Neurobiology. Annual Review of Psychology, 48(1), 547-572.

Furnham, A., Trew, S., \& Sneade, I. (1999). The Distracting Effects of Vocal and Instrumental Music on the Cognitive Test Performance of Introverts and Extroverts. Personality and Individual Differences, 27(2), 381-392.

Grout, D. J., Burkholder, J. P., \& Palisca, C. V. (2010). A History of Western Music (8th ed.). New York: W.W. Norton.

Hall, P. (1998). The Relationship Between Types of Rap Music and Memory in African American Children. Journal of Black Studies, 28(6), 802-814. Retrieved from http://www.jstor.org/ stable/2784818

Ho, Y. C., Cheung, M. C., \& Chan, A. S. (2003). Music Training Improves Verbal but Not Visual Memory: Cross-Sectional and Longitudinal Explorations in Children. Neuropsychology, 17(3), 439.

Jenkins, J. S. (2001). The Mozart Effect. Journal of the Royal Society of Medicine, 94(4), 170- 172.

Jurkovic, A., Anderson, C., Myklejord, D., Levin, C., \& Lotz, A. (2013). The Effect of Music Tempo on Memory Retention.
Limbic System: Amygdala (Section 4, Chapter 6) Neuroscience Online: An Electronic Textbook for the Neurosciences | Department of Neurobiology and Anatomy - The University of Texas Medical School at Houston. (n.d.). Retrieved November 23, 2016, from http://neuroscience.uth.tmc.edu/s4/chapter06. html

Mastin, L. (2010). Types of Memory - The Human Memory. Retrieved December 13, 2016, from http://www.humanmemory.net/types.html

Memory Puzzle. (n.d.). Retrieved January 22, 2017, from http:// www.clarity-media.co.uk/memory-test.php

Meyer, Leonard B. (1956). Emotion and Meaning in Music. Chicago: Chicago University Press.

Reaves, S., Graham, B., Grahn, J., Rabannifard, P., \& Duarte, A. (2015). Turn Off the Music! Music Impairs Visual Associative Memory Performance in Older Adults. The Gerontologist, gnu113.

Reading Comprehension Worksheets. (n.d.). Retrieved January 22, 2017, from http://www.ereadingworksheets.com/freereading-worksheets/reading-comprehension-worksheets/

Rickard, N. S., Wong, W. W., \& Velik, L. (2012). Relaxing Music Counters Heightened Consolidation of Emotional Memory. Neurobiology Of Learning And Memory, 97(2), 220-228. doi: 10.1016/j.nlm.2011.12.005

Silverman, M. J., \& Schwartzberg, E. T. (2014). Effects of Voice Timbre and Accompaniment on Working Memory as Measured by Sequential Monosyllabic Digit Recall Performance. Journal Of Music Therapy, 51(2), 171-185. doi:10.1093/jmt/thu009

Sridharan, D., Levitin, D. J., Chafe, C. H., Berger, J., \& Menon, V. (2007). Neural Dynamics of Event Segmentation in Music: Converging Evidence for Dissociable Ventral and Dorsal Networks. Neuron, 55(3), 521-532.

True Random Number Service. (n.d.). Retrieved January 29, 2017, from www.random.org

Virtala, P., Huotilainen, M., Putkinen, V., Makkonen, T., \& Tervaniemi, M. (2012). Musical Training Facilitates the Neural Discrimination of Major Versus Minor Chords in 13-year-old Children. Psychophysiology, 49(8), 1125-1132. doi:10.1111/j.1469-8986.2012. 01386.x

Wharton, R., \& Shaffer, K. (Eds.). (2014). Open Music Theory - Open Music Theory. Retrieved December 13, 2016, from http://openmusictheory.com/

Willimek, B. (2013). Music and Emotions: Research on the Theory of Musical Equilibration (die Strebetendenz-Theorie). 


\section{APPENDIX A: MEMORY TESTS Control Test}

Gerry was having a bad day. He had been up since 6am, though it felt like he'd never slept - a fault with his alarm clock meant that it went off every 15 minutes from 1:45am onwards! His day continued badly: his toast was burnt, and there was no strawberry jam left, and he was also out of Earl Grey tea.

At work, three meetings came, all one after the other. That was the danger of being the manager of thirty-two employees. The first meeting was with the senior marketing manager, who gave a dull presentation over something unmemorable. The accounts manager, who he saw next, gave a financial projection for the next six months - boring Gerry to tears in the process.

Gerry's final meeting was with his boss, Malcolm, who wanted to know why three team members had left the company in the last two months and why sick days were up $12 \%$ this year. With a team building day in the Lake District just one week away, Gerry assured his boss that things would improve soon. He stopped short of mentioning his theory that Malcolm's strict targets were the cause of lower morale in the team and the consequences he had picked up on.

When Gerry got home at 7:15pm, the answering machine was flashing with five messages, and he also realized that he'd left his mobile phone in the office. After returning his calls, Gerry was finally able to relax for the evening. He sat down to watch a soap opera on TV with a large glass of orange juice and his favorite dinner, only for there to be a power cut. What a day!

\section{Memory Test Questions}

Directions: After reading the story, choose the best answer for each question. Circle one answer.

1) What time did Gerry get up?
a. 1:45 am
b. 6:00 am
c. $7: 15 \mathrm{am}$
d. 10:00 am

2) When did the alarm start going off?
a. 2:00 am
b. $4: 45 \mathrm{am}$
c. 1:45 am
d. 12:00 am

3) Who were the first two people Gerry had meetings with?
a. Senior market manager, boss
b. Accounts manager, senior market manager
c. Senior market manager, accounts manager
d. Boss, accounts manager

4) How many employees does Gerry manage?
a. 35
b. 32
c. 33
d. 29

5) Gerry's boss' name is
a. Malcolm
b. Steve
c. Ed
d. Andrew

6) Where was the team building day being held?
a. Lake District
b. Township Central
c. South Grove
d. Harper Creek

7) What percentage change in sick days had there been recently?
a. $15 \%$
b. $12 \%$
c. $20 \%$
d. $13 \%$

8) What two breakfast items did Gerry not have at home?
a. Honey, toast
b. Peanut butter, eggs
c. Orange juice, milk
d. Strawberry jam, Earl Gray tea

9) What did Gerry think caused low morale in the office?
a. Not enough employee bonuses
b. Too much workload
c. Preposterous rules and regulations
d. His boss's strict targets

10) What time did Gerry get home after work?
a. $7: 15 \mathrm{pm}$
b. $8: 00 \mathrm{pm}$
c. $6: 00 \mathrm{pm}$
d. $5: 00 \mathrm{pm}$

Answers: B, C, C, B, A, A, B, D, D, A

\section{Experimental Test}

Jacob hated finishing things almost as much as he loved starting them. He'd gotten into a million activities, but never stuck with any of them long enough to get any good. He begged his mother for a guitar so he could play Black Eyed Peas songs to Angie, a girl he liked, but after he finally got one for Christmas, he found that guitars don't play themselves. He took a few lessons, but strumming the strings hurt his fingers and he didn't like holding the pick, so now the fivehundred-dollar guitar lives under his bed.

After reading an ad in one of his comic books, Jacob wanted a metal detector so he could find buried pirate treasure. He mowed lawns all summer and shoveled driveways all winter. By spring, he saved $\$ 200$, and he purchased the detector. He beeped it around the park for a while, but he soon found that no pirates had ever been there or left any treasure. Although he found forty-seven cents and tons of bottle caps, he buried the metal detector in his closet.

Given Jacob's history with hobbies, it was no surprise that his father was reluctant to buy him a magician's kit for his birthday. But Jacob's father was reminded of his own youth long ago, so when his birthday came around, Jacob was both surprised and pleased to find the magician's kit with a big bright bow on it.

Jacob opened the box and unwrapped the many parts in the kit. As he continued, a TV commercial caught his attention. "Hey kids! Have you ever wanted to go to space? Experience what it's like to be an astronaut? Now you can." Jacob walked away from the kit and stared at the TV longingly. "For only $\$ 195$ you can go to space camp and live life like an astronaut. Enroll now for a once in a lifetime experience." Jacob's cry rang through the house as he yelled, "MOM!" He now knew what his true purpose in life was. 


\section{Memory Test Questions}

Directions: After reading the story, choose the best answer for each question. Circle one answer.

1. Why does Jacob stop playing the guitar?

a. It hurt his fingers.

b. He'd rather play drums.

c. It was too easy

d. He failed math

2. To whom did Jacob want to play Black Eyed Peas songs?
a. Alex
b. Angie
c. Mom
d. Dad

3. Why does Jacob decide that he wants a metal detector?
a. He sees a man at the park with one.
b. His father had one as a child.
c. He saw a TV commercial for one.
d. He read an ad for one in a comic book.

4. What does Jacob do to be able to buy the metal detector?
a. He asks his mom.
b. He asks his dad.
c. He shovels driveways and mows lawns.
d. He does all of these things to get what he wants.

5. When did Jacob buy the metal detector?
a. In the fall
b. In the summer
c. In the spring
d. In the winter

6. Why doesn't Jacob's father want to get him the magician's kit for his birthday?
a. Jacob failed math class.
b. Jacob quits too many expensive activities.
c. Jacob has been mean to his younger brother.
d. Jacob went to the park without permission.

7. Why does Jacob's father buy him the magician's kit?
a. Jacob mowed the lawn.
b. Jacob reminded his father of himself.
c. Jacob bought ice cream for his brother.
d. Jacob found his father's key ring.

8. What distracts Jacob from the magician's kit?
a. A TV commercial
b. His father
c. The kitchen table
d. A comic book

9. Which happened first in the text?
a. Jacob asked his dad for the magician's kit.
b. Jacob mowed lawns.
c. Jacob got a guitar for Christmas.
d. Jacob shoveled driveways.

10. Which happened last in the text?
a. Jacob saved up $\$ 200$.
b. Jacob took guitar lessons.
c. Jacob found forty-seven cents in the park.
d. Jacob was influenced by a comic book.

\section{APPENDIX B: MUSICAL SCORES Musical Score in D Major}

Prelude in D major
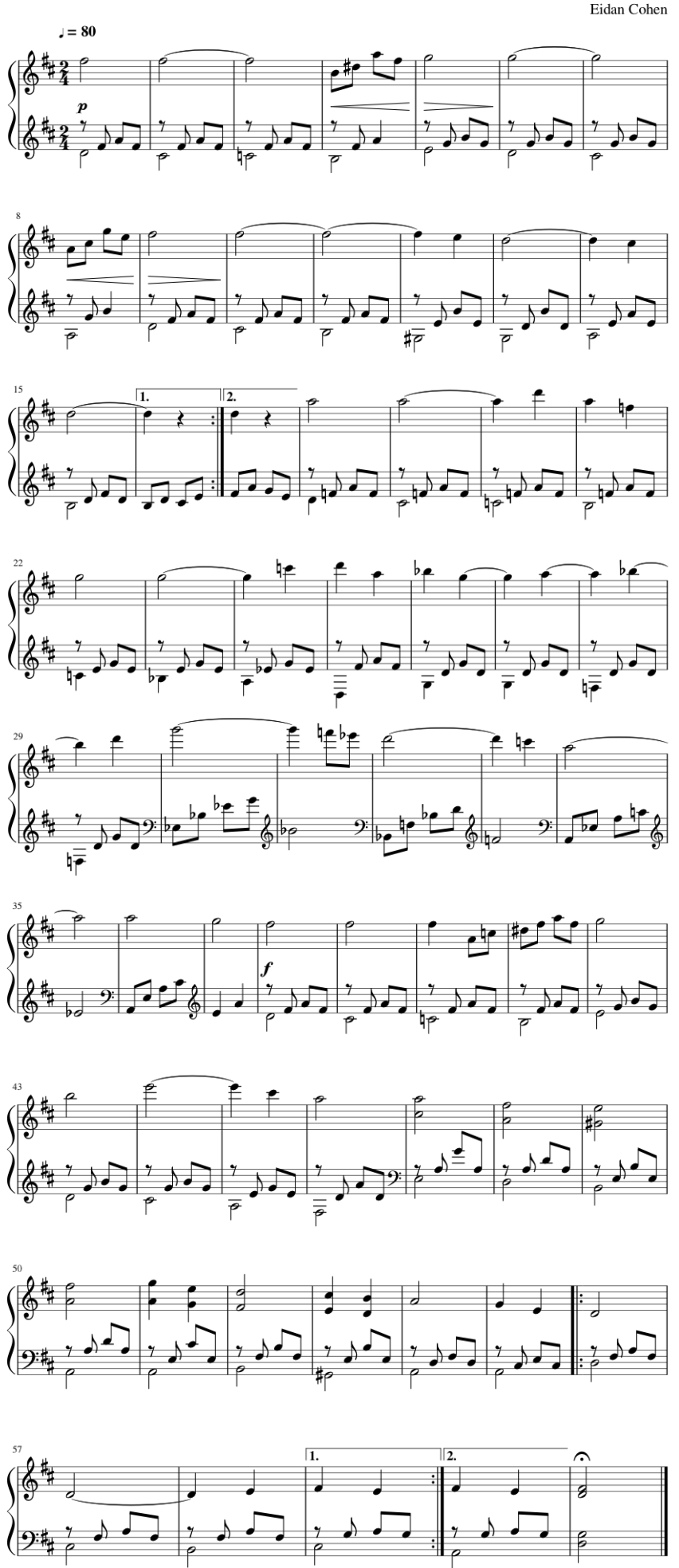


\section{Musical Score in D Minor}

D Minor
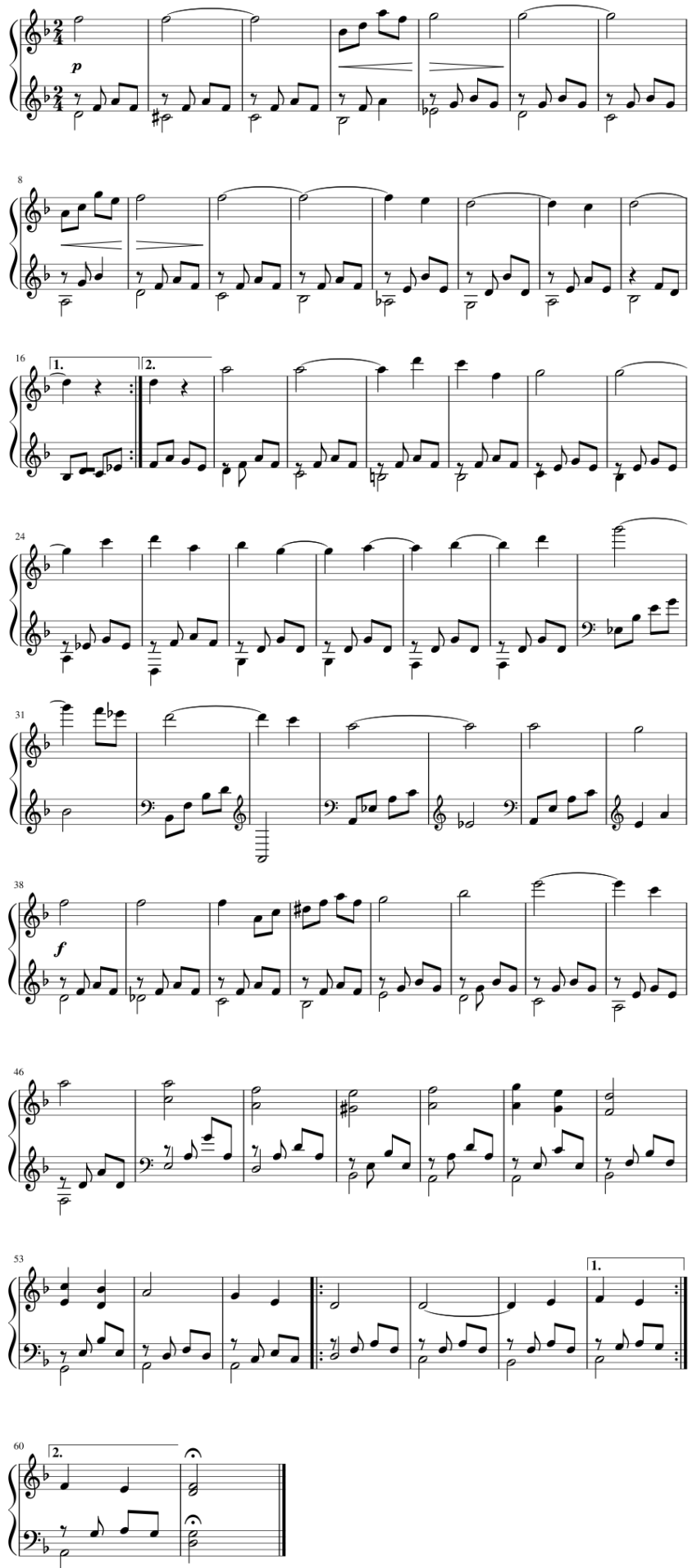

\section{APPENDIX C: RESULTS DATA Raw Data}

Below are the raw scores (10 maximum possible points) for all the students. (Student's Control score is adjacent to their experimental score-example: in the first row, Group A student's control score was 8; their experimental score was 9 , etc.) Note: * = students who indicated either an intermediate or advanced level of musical ability

\begin{tabular}{|r|r|r|r|}
\hline \multicolumn{1}{|c|}{ Control A } & \multicolumn{1}{|c|}{ A } & Control B & B \\
\hline 8 & 9 & 9 & $10^{*}$ \\
\hline 7 & 8 & 5 & $7^{*}$ \\
\hline 5 & 6 & 5 & 9 \\
\hline 3 & $3^{*}$ & 8 & 7 \\
\hline 10 & $10^{*}$ & 8 & $9^{*}$ \\
\hline 7 & $9^{*}$ & 6 & 8 \\
\hline 6 & $7^{*}$ & 5 & $9^{*}$ \\
\hline 6 & $6^{*}$ & 6 & $7^{*}$ \\
\hline 7 & 9 & 6 & 6 \\
\hline 7 & $10^{*}$ & 4 & $6^{*}$ \\
\hline 10 & 10 & & \\
\hline
\end{tabular}

\section{Boxplot of Raw Scores}

Below is a boxplot showing all the raw scores.

Control

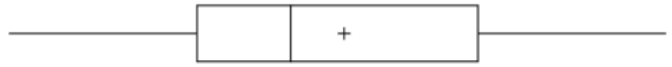

A

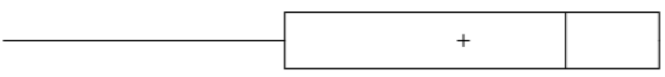

B

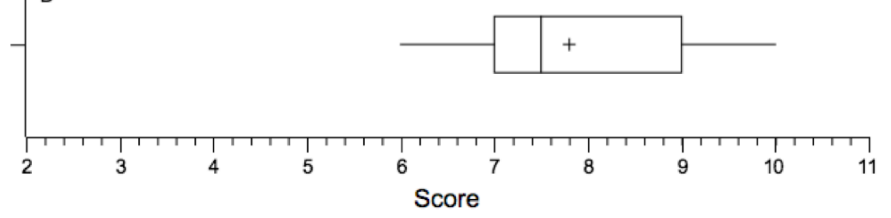

\section{APPENDIX D: STUDENT QUESTIONNAIRE General Demographics Information}

Please circle your response.

1.What is your grade level?

$$
\begin{array}{llll}
9 & 10 & 11 & 12
\end{array}
$$

2. What is your gender? Male Female

3. Please indicate your musical knowledge:

- I do not know anything about music theory and/or am not involved in any musical activities (ex: band, choir, orchestra, solo instrumental playing)

- I know some music theory and/or am involved in a musical activity at a beginner level

- I know music theory and/or am involved in a musical activity at an intermediate level 


\section{SOCIAL SCIENCES}

- I know music theory well and/or am involved in a musical activity at an advanced level

4. Could you recognize if the music played during the reading was in a major or minor key? (if yes, please circle one)

Please do not circle randomly. Skip this question if you do not know Major Minor

5. Did you feel the music played during the passage reading was distracting (if yes, please complete \#6, if no, you may leave it blank).

$$
\text { Yes No }
$$

6. Please circle the number that you feel best represents your level of distraction during the reading.
12
3

Slightly distracting,

I had few problems

Extremely distracting,

concentrating

I was unable to focus

Thank you so much for participating!

\section{Questionnaire Student Responses}

\begin{tabular}{|c|c|c|c|c|c|c|c|c|c|}
\hline \multicolumn{2}{|c|}{$\begin{array}{l}\text { Number of } \\
\text { students in } \\
\text { each grade } \\
\text { level }\end{array}$} & \multicolumn{2}{|c|}{$\begin{array}{l}\text { Gender } \\
(\mathrm{F}, \mathrm{M})\end{array}$} & \multicolumn{2}{|c|}{$\begin{array}{l}\text { Number of students } \\
\text { with each musical } \\
\text { skill level of } \\
\text { knowledge }\end{array}$} & \multicolumn{2}{|c|}{$\begin{array}{l}\text { Number of } \\
\text { students who } \\
\text { indicated a guess } \\
\text { of major/minor } \\
\text { (correct answer: } \\
\text { minor) }\end{array}$} & \multicolumn{2}{|c|}{$\begin{array}{l}\text { Number of } \\
\text { students who } \\
\text { indicated some } \\
\text { form of } \\
\text { distraction } \\
\text { (scale of 1-5) }\end{array}$} \\
\hline 9 & 1 & $\mathrm{~F}$ & 6 & None & 2 & Major & 2 & 1 & 0 \\
\hline 10 & 2 & M & 2 & Beginner & 2 & Minor & 3 & 2 & 1 \\
\hline 11 & 2 & & & Intermediate & 1 & & & 3 & 0 \\
\hline 12 & 5 & & & Advanced & 5 & & & 4 & 1 \\
\hline & & & & & & & & 5 & 0 \\
\hline
\end{tabular}

Table D1 (Group A).

\begin{tabular}{|c|c|c|c|c|c|c|c|c|c|}
\hline \multicolumn{2}{|c|}{$\begin{array}{l}\text { Number of } \\
\text { students in } \\
\text { each grade } \\
\text { level }\end{array}$} & \multicolumn{2}{|c|}{$\begin{array}{l}\text { Gender } \\
(\mathbf{F}, \mathbf{M})\end{array}$} & \multicolumn{2}{|c|}{$\begin{array}{l}\text { Number of students } \\
\text { with each musical } \\
\text { skill level of } \\
\text { knowledge }\end{array}$} & \multicolumn{2}{|c|}{$\begin{array}{l}\text { Number of } \\
\text { students who } \\
\text { indicated a guess } \\
\text { of major/minor } \\
\text { (correct answer: } \\
\text { major) }\end{array}$} & \multicolumn{2}{|c|}{$\begin{array}{l}\text { Number of } \\
\text { students who } \\
\text { indicated some } \\
\text { form of } \\
\text { distraction } \\
\text { (scale of 1-5) }\end{array}$} \\
\hline 9 & 3 & $\mathrm{~F}$ & 9 & None & 0 & Major & 1 & 1 & 0 \\
\hline 10 & 2 & M & 2 & Beginner & 4 & Minor & 4 & 2 & 3 \\
\hline 11 & 3 & & & Intermediate & 2 & & & 3 & 0 \\
\hline 12 & 3 & & & Advanced & 5 & & & 4 & 3 \\
\hline & & & & & & & & 5 & 0 \\
\hline
\end{tabular}

Table D2 (Group B). 